\title{
Ein Beitrag zu der v. Weckerschen Tätowierung von Hornhantnarben. \\ Von
}

\author{
Dr. L. Kugel, \\ derzeit Augenarzt am Caritasspitale in Bukarest.
}

In den letzten drei Jahren bediene ich mich, behufs Tätowierung von Hornhautflecken (anstatt der üblichen Methode mittels Nadeln), der Messer, entweder des Graefeschen Starmessers, oder noch besser der Iridektomielanze. Ich mache mit derselben eine Anzahl (bis zu 30) Schnitte, indem ich sie möglichst nahe der Oberfläche ins Narbengewebe vorschiebe, bis ich einen ungefähr $1 \frac{1}{2}$ bis $2 \mathrm{~mm}$ langen Schnitt herausbekomme. - Ich erhalte auf diese Weise eine Anzahl schwarzer Linien, zwischen welchen man mit der Lupe weisses Narbengewebe sieht. Nach etlichen Wochen erscheinen die schwarzen Striche verbreitert, oder man sieht ganze Pigmenthaufen mit Ausläufern, ungefähr wie bei Retinitis pigmentosa; dabei ist das zwischen diesen Linien oder Pigmenthaufen gelegene Gewebe nicht mehr weiss, wie unmittelbar nach der Operation, sondern etwas dunkler, wodurch die Narbe mehr gleichförmig gefärbt erscheint.

Ich bediene mich (was auch von andern Augenärzten als vorteilhaft erwähnt wird) einer möglichst dicken, breiigen Tuschmasse, und lasse dieselbe nach jeden drei bis vier Sekunden wegwischen, da sie sonst durch Tränenflüssigkeit bald zu sehr verdünnt wird; ich bin dadurch gleichzeitig während der Operation möglichst oft orientiert, was ich bereits ausgerichtet habe, wie viel ich noch $\mathrm{zu}$ tätowieren habe usw.

Die Vorteile der Messeroperation gegenüber der Nadeloperation sind folgende:

Die Tusche wird, wenn mit dem Messer operiert wird, vom Auge besser vertragen. - Es zeigt sich dies durch folgende zwei Fakten: die nachoperative Entzündung ist eine geringere als bei der Nadeloperation, und die Tusche bleibt besser haften.

Man sieht nämlich den nächsten Tag beim Verbandwechsel das Auge 
weniger irritiert, die Narbe entweder ganz oder fast so schwarz wie unmittelbar nach der Operation, und auf der Verbandwatte gar keine oder eine relativ geringe Quantität der Tuschmasse. - Eine Folge der geringgradigern Entzündung und des bessern Anhaftens der Tuschmasse ist die relativ kürzere Heilungsdauer.-Die Heilungsdauer ist eine kürzere, weil durch schnelleres Verschwinden der Entzündung die nächste Sitzung (wo solche sich als nötig erweist) schneller folgen kann, und weil infolge des bessern Anhaftens der Tusche überhaupt weniger Sitzungen notwendig sind.

Dies sind im allgemeinen die Vorteile, die ich in dem Operieren mit dem Messer sehe.

Ich will noch bemerken, dass ich jetzt in Fällen die Tätowierung vornehme, bei welchen ich, wenn es sich um die Nadeloperation handeln würde, die Operation nicht unternehmen würde; ich meine damit Falle, wo der grösste Teil der Hornhaut infolge ausgedehnter Destruktion durch dichtes Narbengewebe ersetzt ist. Es sind mir nämlich derartige Kranke vorgekommen, welche trotz des geringern kosmetischen Effektes die Tätowierung dem Tragen eines künstlichen Auges vorzogen; ich bekomme jetzt auch in diesen Fällen zufriedenstellende Resultate heraus, was ich von der Operation mittels Nadeln nicht sagen kann, da in fast allen derartigen Fällen, die ich mittels Nadeln operierte, die Tuschmasse ganz oder fast ganz mit saunt der oberflächlichen Narbenschicht abgestossen wurde. - Es ist aber in diesen Fällen, selbst wenn mit dem Messer operiert wird, das Reüssieren der Operation an gewisse Bedingungen geknüpft; es muss nämlich die Narbe glatt, mit einem vollständigen Epitheliumüberzug versehen sein; ist das Narbengewebe entzündet, sind oberflächliche Epithelialverluste und pericorneale Rötung vorhanden, so wird man mit dem Messer auch nichts ausrichten; die Tuschmasse bleibt in solchen Fallen nicht haften, und man findet den nächsten Tag beim Verbandwechsel die ganze oberflächliche Schicht der Narbe mit samt der ganzen Tusche auf der Verbandwatte.

Die Anzahl der ron mir mit dem Messer Operierten beträgt bis jetzt ungefahr siebzig. - Ich hatte jedoch bereits nach den ersten 10 bis 15 Fällen die Uberzeugung gewonnen, dass die Messeroperation bedeutende Vorteile gegenüber der mittels Nadeln hat, eine Überzengung, die sich mit dem Wachsen der Operationszahl noch verstärkte. Das angestrebte Ziel wird mit dem Messer in schnellerer, sicherer und leichterer, den Kranken weniger molestierender Weise erreicht, als wenn mit Nadeln operiert wird. 